International Journal of Current Advanced Research

ISSN: O: 2319-6475, ISSN: P: 2319 - 6505, Impact Factor: SJIF: 5.995

Available Online at www.journalijcar.org

Volume 6; Issue 3; March 2017; Page No. 2803-2804

DOI: http://dx.doi.org/10.24327/ijcar.2017.2804.0109

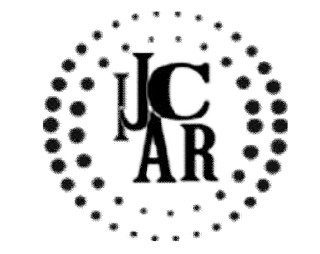

Research Article

\title{
INFLUENCE OF CURING TIME AND BONDING AGENT IN RESPECT TO DISCOLOURATION OF COPOSITE RESTORATION
}

\section{S.Syed Shihaab E Noor and A.C.Kanthaswamy}

Saveetha Dental College

\section{A R T I C L E I N F O}

\section{Article History:}

Received $20^{\text {th }}$ December, 2016

Received in revised form $15^{\text {th }}$ January, 2017

Accepted $16^{\text {th }}$ February, 2017

Published online $28^{\text {th }}$ March, 2017

Key words:

Curing Time, Discolouration, Restoration

\begin{abstract}
A B S T R A C T
Aim - to evaluate influence of bonding agent and curing time in regards to discolouration of composite

Objective - the objective of the study is to find the effect of curing time and bonding agent in regard to discolouration of composite material

Background - dental composite resins are types of synthetic resins which are used in dentistry as restorative material or adhesives. Synthetic resins evolved as restorative materials since they were insoluble, aesthetic, insensitive to dehydration, easy to manipulate and reasonably inexpensive. One of the main disadvantage of light cure is the tendency to discolour in course of time.
\end{abstract}

Reason : this research is carried out to evaluate influence of bonding agent and curing time in regards to discolouration of composite.

Copyright $(2017$ S.Syed Shihaab E Noor and A.C.Kanthaswamy. This is an open access article distributed under the Creative Commons Attribution License, which permits unrestricted use, distribution, and reproduction in any medium, provided the original work is properly cited.

\section{INTRODUCTION}

Tasteful disappointment is a standout amongst the most widely recognized explanations behind the substitution of reclamations. A decent blend of the tooth shading and the underlying shade of the material before curing is a critical clinical element for an effective result. Regardless, this blend must stay after the material is totally cured and all through the reclamation's life-time. Discolouration of tooth-hued, sap based materials might be brought about by inborn or outward factors. $^{1,2}$ the inherent components include the discolouration of the tar material itself, for example, the modification of the tar grid and of the interface of the framework and the fillers. Substance discolouration has been ascribed to a change or oxidation in the amine quickening agent, oxidation in the structure of the polymer grid, and oxidation of the unreacted pendant methacrylate groups. ${ }^{3,4}$ Outward elements for discolouration incorporate recoloring by adsorption or retention of colorants accordingly of defilement from exogenous sources. The level of discolouration from exogenous sources fluctuates as per the oral cleanliness, the eating-drinking and smoking propensities for the patients. ${ }^{5,6}$ The recoloring of polymeric materials by hued arrangements, espresso and tea, nicotine, and drinks has been accounted for in numerous past studies. ${ }^{1-7}$ these substances can prompt to yellow-cocoa recolors in teeth and on the surfaces of the gum

*Corresponding author: S.Syed Shihaab E Noor

Saveetha Dental College composites. ${ }^{8}$ The motivation behind this review was to assess the recoloring limit of various sorts of tar based composite materials upon introduction to simulated salivation, tea, coffee, coco cola. The speculation of this review was that recoloring limit of the tar composite materials is identified with the sort of the recoloring arrangement utilized.

\section{MATERIALS AND METHOD}

Materials used were A1 shade composite, LCR unit, stopwatch, bonding agent, coco cola, tea, coffee. 50 composite sample in form of cakes were made of dimension $10 \mathrm{~mm}$ diameter and $2 \mathrm{~mm}$ thickness. These 50 samples were divided into 2 groups consisting of 25 samples in each. One set of 25 samples were subjected to curing and on other set bonding agent was applied on the surface of composite. These 25 samples in each set were further divided into 5 sets consisting of 5 samples in each set. Each set of samples were cured then for $10 \mathrm{sec}, 15 \mathrm{sec}, 20 \mathrm{sec}, 25 \mathrm{sec}$, $30 \mathrm{sec}$ respectively. After thermocycline These cured composites were kept in coco cola for 30 days, followed by tea for 30 days, followed by coffee for 30 days. Then these samples were observed for discolouration.

\section{RESULT}

The results were grouped into two categories, one with bonding agent on the surface Of composite and the other set without application of bonding agent on the surface of composite. It was observed that the samples without bonding agent showed more discolouration than the 
samples covered with bonding agent. The samples which were cured for shorter time showed more discolouration than the sample which was cured for $30 \mathrm{sec}$. In the samples without bonding agent it was observed that the sample cured for $10 \mathrm{sec}$ got converted from A1 shade to A3 shade, the sample cured for $15 \mathrm{sec}$ showed discoluration from $\mathrm{A} 1$ to $\mathrm{B} 2$ shade, the sample cured for $20 \mathrm{sec}$ showed discoluration from A1 to C1 shade, the sample cured for $25 \mathrm{sec}$ showed discoluration from A1 to A2 shade, the sample cured for $30 \mathrm{sec}$ showed discoluration from A1 to A2 shade. In the samples with bonding agent on the surface it was observed that, the sample cured for $10 \mathrm{sec}$ showed discoluration from A1 to B2 shade, the sample cured for $15 \mathrm{sec}$ showed discoluration from A1 to A2 shade, the sample cured for $20 \mathrm{sec}$ showed discoluration from A1 to B1 shade, the sample cured for $25 \mathrm{sec}$ showed discoluration from A1 to A1 shade, the sample cured for 30sec showed discoluration from A1 to A1 shade. These discoluration were observed using study guide.

\section{DISCUSSION}

This study shows that the samples without bonding agent showed more discolouration than the samples covered with bonding agent. The samples which were cured for shorter time showed more discolouration than the sample which was cured for $30 \mathrm{sec}$. The samples which had bonding agent on the top and were cured for $30 \mathrm{sec}$ showed no characteristics of discoluration. Composite gums are remedial materials that have been broadly embraced for tasteful techniques because of their great properties and force of union to veneer and dentin. Be that as it may, one of their inconveniences is the shading change with time, which is a noteworthy explanation behind supplanting restorations ${ }^{13}$. There are numerous outward and natural elements that impact shading solidness of composite resins ${ }^{9,10,11,13,15}$. Consequences of this review were like those found by Pires-de-Souza, et $a .^{12}$ (2007) LED hardware additionally demonstrated lower shading changes for a cross breed tar, when contrasted with a customary halogen unit

For coffee, there was a color change in the resin since the first $24 \mathrm{~h}$ of immersion, similar to that observed by Yazici, et $a l .{ }^{16}$ (2007), when the same composite resin was examined. This change progressed at each evaluation period. According to Soares, et al. ${ }^{13}$ (2007) and Villalta, et al. ${ }^{15}$ (2006), the staining capacity of the composite resin is related to extrinsic factors, such as the pigment agent is subjected to, and to intrinsic factors, such as loading particles and resinous matrix. In this study, the extrinsic factors related to color change were observed. However, the intrinsic factors cannot be left aside, since a recently developed composite resin was used. Topcu, et $a l .{ }^{14}$ (2009) has shown that the effect of the staining solutions might be different for distinct materials and found that a nanofilled composite resin (Filtek Supreme) had the least discoloration among other tested composite materials (Filtek Z250, Charisma and Quadrant).

\section{CONCLUSION}

From this study it is clear that composite without bonding agent showed more discolouration than the composites covered with bonding agent. The composites which were cured for shorter time showed more discolouration than the composite which was cured for 30 sec. Hence we can conclude that to prevent discolouration composite should be cured for $30 \mathrm{sec}$ or more.

\section{Reference}

1. Um $\mathrm{cm}$, ruyter ie. Staining of resin-based veneering materials with coffe and tea. Quintessence int. 1991;22:377-386. [pubmed]

2. Yannikakis sa, zissis aj, polyzois gl, caroni c. Colour stability of provisional resin restorative materials. $J$ prosthet dent. 1998;80:533-539. [pubmed]

3. Ruyter ie. Composites- characterization of composite filling materials: reactor response. $A d v$ dent res. 1988;2:122-129. [pubmed]

4. Asmussen e. Factors affecting the colour stability of restorative resins. Acta odontol scand. 1983;41:1118. [pubmed]

5. Satou n, khan am, matsumae i, satou j, shintani h. In vitro colour change of composite- based resins. Dent mater. 1989;5:384-387. [pubmed]

6. Raptis cn, powers jm, fan $\mathrm{pl}$, et al.J oral rehabil. 1982;9:367-371. [pubmed]

7. Gross md, moser jb. A colourimetric study of coffee and tea staining of four composite resins. $J$ oral rehabil. 1977;4:311-322. [pubmed]

8. Khokhar za, razzoog me, yaman p. Colour stability of restorative resins. Quintessence int.1991;22:733737. [pubmed]

9. Janda R, Roulet JF, Latta M, Steffin G, Rüttermann S. Color stability of resin-based filling materials after aging when cured with plasma or halogen light. Eur $J$ Oral Sci. 2005;113:251-257. [PubMed]

10. Mutlu-Sagesen L, Ergün G, Ozkan Y, Semiz M. Color stability of a dental composite after immersion in various media. Dent Mater J.2005;24:382390. [PubMed]

11. Omata Y, Uno S, Nakaoki Y, Tanaka T, Sano H, Yoshida S, et al. Staining of hybrid composites with coffee, oolong tea, or red wine. Dent Mater J. 2006;25:125-131. [PubMed]

12. Pires-de-Souza FC, Garcia LF, Hamida HM, Casemiro LA. Color stability of composites subjected to accelerated aging after curing using either a halogen or a Light emitting Diode source. Braz Dent J. 2007;18:119-123. [PubMed]

13. Soares LES, Cesar ICR, Santos CGC, Cardoso AL, Liporoni PCS, Munin E, et al. Influence of coffee on reflectance and chemistry of resin composite protected by surface sealant. Am J Dent. 2007;20:299304.[PubMed]

14. Topcu FT, Sahinkesen G, Yamanel K, Erdemir U, Oktay EA, Ersahan S. Influence of different drinks on the colour stability of dental resin composites. Eur $J$ Dent. 2009;3:50-56. [PMC free article] [PubMed]

15. Villalta P, Lu H, Okte Z, Garcia-Godoy F, Powers JM. Effects of staining and bleaching on color change of dental composite resins. $J$ Prosthet Dent. 2006;95:137-142. [PubMed]

16. Yazici AR, Celik C, Dayangaç B, Ozgünaltay G. The effect of curing units and staining solutions on the color stability of resin composites. Oper Dent. 2007;32:616-622. [PubMed] 